\title{
The investigation and management of severe hyponatraemia
}

\section{Crook}

\section{The importance of the laboratory in patient care}

$\mathrm{H}$ yponatraemia is probably the most common electrolyte disturbance encountered in clinical practice. Despite this, the best way to manage this condition is debated and not always fully appreciated. Indeed, there may be problems in both the investigation and its treatment, as is highlighted in the paper by Saeed and colleagues in this month's edition. ${ }^{1}$

One problem would seem to be that some clinicians experience difficulties in investigating the causes of hyponatraemia. It is here where the clinical biochemistry laboratory and chemical pathologist can play an important role in facilitating optimal patient care. Interestingly, Saeed and colleagues showed that rarely did patients with severe hyponatraemia have their urine osmolality or sodium checked. ${ }^{1}$ In such cases, it is difficult to see how the cause of the hyponatraemia could be clearly established. This of course is of fundamental importance, because the management of hyponatraemia should differ according to its aetiology. ${ }^{2-4}$ Indeed, in the paper by Saeed et al it is reported that some cases of hyponatraemia may incorrectly be attributed to the syndrome of inappropriate antidiuretic hormone (SIADH) because the diagnostic criteria had not been fulfilled. ${ }^{1}$ This confirms earlier hospital studies and suggests that the problem could be widespread. ${ }^{5}$

SIADH may be over diagnosed and the diagnosis is usually made by finding a urine sodium concentration of greater than $20 \mathrm{mmol} /$ litre in the presence of euvolaemic hyponatraemia or low plasma osmolality and in the absence of hypovolaemia, oedema, impaired renal function, the use of diuretics, adrenal insufficiency, or hypothyroidism. According to the Barter and Schwartz criteria for SIADH, the urine osmolality is inappropriately concentrated in relation to the plasma osmolality-that is, in the hypo-osmal state the urine is not maximally dilute.

The clinical biochemistry laboratory also has a role in excluding pseudohyponatraemia, where an increase in the non-aqueous phase of plasma gives a spuriously low sodium concentration if assayed by techniques that rely on plasma dilution. This has been described in severe hypertriglyceridaemic or hyperproteinaemic samples. Translocational hyponatraemia also needs excluding, as can be seen with hyperglycaemia or mannitol administration. Here, translocation of water from the intracellular fluid space occurs or the prevention of water entry into cells is associated with increased plasma osmolality. ${ }^{2-4}$

"latrogenic postoperative hyponatr-
aemia, as a result of the
injudicious use of isotonic
dextrose, is still tragically
encountered, and can result in
neurological damage or death"

Ignorance of the effects of hyponatraemia unfortunately still occurs. For example, iatrogenic postoperative hyponatraemia, as a result of the injudicious use of isotonic dextrose, is still tragically encountered, and can result in neurological damage or death. ${ }^{7}$ Premenopausal women and children are more susceptible to this, as are the elderly, particularly if on diuretics or certain antidepressant drugs. Furthermore, there is also uncertainty about the most appropriate treatment of severe hyponatraemia because rapid correction can induce cerebral myelinolysis, whereas too slow correction may allow cerebral oedema. There are now data suggesting that acute (present for less than 48 hours) severe hyponatraemia is a medical emergency, which should be treated rapidly to bring the plasma sodium to about $130 \mathrm{mmol} /$ litre. $^{2-4}$ Conversely, in chronic severe hyponatraemia (present for more than 48 hours), where there is no cerebral oedema, the slow correction of plasma sodium by less than $0.5 \mathrm{mmol} /$ hour and not exceeding a plasma sodium concentration of $130 \mathrm{mmol} /$ litre is recommended. Close monitoring of plasma and urine sodium is required to ensure safe correction. ${ }^{2-4}$ Present treatment options may consist of infusions of normal or hypertonic saline, the use of loop diuretics, or fluid restriction depending upon the cause and severity of the hyponatraemia. In addition, there is ongoing research looking at the potential of vasopressin V2 receptor antagonists in the treatment of some forms of hyponatraemia. ${ }^{4}$

In summary, the clinical biochemistry laboratory and chemical pathologists have roles in the diagnosis and treatment monitoring of patients with hyponatraemia. Doctors need to be aware of the clinical implications of severe hyponatraemia and how to diagnose and treat it correctly. It may also be useful to reflect upon the words of Lane and Allen that "iatrogenic hyponatraemia is inexcusable. It is time that doctors woke up to the risks".

J Clin Pathol 2002;55:883

\section{Author's affiliation}

M Crook, Clinical Biochemistry, University Hospital Lewisham, Lewisham, London SE13 6LH, UK

Correspondence to: $\operatorname{Dr} M$ Crook, Clinical Biochemistry, University Hospital Lewisham, Lewisham, London SE 13 6LH, UK:

Martin.Crook@uhl.nhs.uk

\section{REFERENCES}

1 Saeed BO, Beaumont D, Handley GH, et al. Severe hyponatraemia: investigation and management in a district general hospital. $J$ Clin Pathol 2002;55:893-6.

2 Fraser CL, Arieff Al. Epidemiology, pathophysiology and management of hyponatraemic encephalopathy. Am J Med 1997; 102:67-77.

3 Ayas JC, Arieff AL. Brain damage and post-operative hyponatraemia: the role of gonder. Neurology 1996;46:323-8.

4 Gross P, Reimann D, Henschkowski J, et al. Treatment of severe hyponatraemia; conventional and novel aspects. J Ám Soc Nephrol 2001;12(suppl): 10-14

5 Crook M, Velauthar U, Moran L, et al. Review of investigation and management of severe hyponatraemia in a hospital population. Ann Clin Biochem 1999;36:158-62

6 Barter F, Schwartz WB. The syndrome of inappropriate secretion of antidiuretic hormone. Am J Med 1967;42:790-806

7 Lane N, Allen K. Hyponatraemia after orthopaedic surgery. BMW 1999;318:1363-4 